\title{
A MEDIAÇÃO DA INFORMAÇÃO NA NARRATIVA ORAL E NA HISTÓRIA DE VIDA: PROPOSIÇÕES DIALOGAIS
}

THE MEDIATION OF INFORMATION INTO ORAL NARRATIVE AND IN THE LIFE STORY: DIALOGICAL PROPOSITIONS

LA MEDIACIÓN DE LA INFORMACIÓN EN LA NARRATIVA ORAL Y EN LA HISTORIA DE LA VIDA: PROPOSICIONES DIALOGALES

${ }^{1}$ Ana Cristina Guimarães Carvalho

${ }^{2}$ Maria Gezilda e Silva Nascimento

${ }^{3}$ Midinai Gomes Bezerra

Universidade Federal do Piauí ${ }^{1}$

Instituto Federal de Educação, Ciência e Tecnologia do Maranhão ${ }^{2}$

Universidade Estadual da Paraíba ${ }^{3}$

Correspondência

${ }^{1}$ Ana Cristina Guimarães Carvalho

Universidade Federal do Piauí

Teresina, PI - Brasil

Email: anacarvalho.biblio@gmail.com

ORCID: http://orcid.org/0000-0001-9444-9666

Submetido em: 22/01/2018

Aceito em: 12/03/2018

Publicado em: 15/03/2018

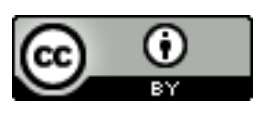

JITA: CF. Reading and story telling. 
RESUMO: Este estudo se propõe a discutir a mediação da informação e suas relações com a narrativa oral e com a história de vida, enquanto potenciais recursos informacionais para a apropriação e construção do conhecimento. Para tanto, a problematização norteadora desta pesquisa se concentra na seguinte indagação: quais as possíveis relações entre a mediação da informação, a narrativa oral e a história de vida no âmbito do fazer bibliotecário? O objetivo é abordar as concepções de mediação da informação a partir do fazer bibliotecário, visando uma aproximação com as perspectivas da narrativa oral e história de vida. Partindo de uma revisão de literatura, o presente trabalho conclui que as narrativas orais e as histórias de vida configuram-se como fenômenos mediacionais no processo de apropriação de informações e construção do conhecimento.

PALAVRAS-CHAVE: Mediação da Informação. História Oral - Narrativas. Bibliotecário Mediador.

ABSTRACT: This survey aims to discuss the information mediation and its relations with the oral narrative and life story as informational resource potentials for appropriation and knowledge construction. Thus, the guiding problem of this research is: what are possible relations among the mediation of information, oral narrative and the life story into the librarian work. The objective is to assess the conceptions of information mediation from the librarian work, seeking an approaching with the perspectives of the oral narrative and life story. From the literature review, this study concludes oral narratives and life stories set up as mediational phenomena in the process of appropriation of information and knowledge construction.

KEYWORDS: Mediation of Information. Oral Story - Narrative. Librarian - Mediator.

RESUMEN: Este estudio se propone a discutir la mediación de la información y sus relaciones con la narrativa oral y con la historia de la vida, en cuanto potenciales recursos informacionales para la apropiación y construcción del conocimiento. Para eso, la problematización rectora de esta investigación se concentra en la siguiente indagación: ¿cuáles las posibles relaciones entre la mediación de la información, la narrativa oral y la historia de la vida en el ámbito del hacer bibliotecario? El objetivo es abordar las concepciones de la mediación de la información desde el hacer bibliotecario, proponiendo una aproximación con las perspectivas de la narrativa oral e historia de la vida. Partiendo de una revisión de literatura, el presente trabajo concluye que las narrativas orales y las historias de la vida se configuran como fenómenos mediacionales en el proceso de apropiación de informaciones y construcción del conocimiento.

PAlABRAS ClAVE: Mediación de la Información. Historia Oral - Narrativa. Bibliotecario - Mediador. 


\section{INTRODUÇÃ̃o}

$\mathrm{Na}$ atualidade, o termo mediação vem emergindo e se consolidando gradativamente, atravessando diversas áreas do conhecimento e assumindo percepções conceituais distintas. Seus estudos compreendem do Direito à Educação, perpassando também pela Comunicação (SILVA, 2015), com cada um de seus aspectos, interessando a uma ciência diferente. Isto se deve em virtude do "caráter múltiplo, plural e coletivo que a mediação possui, enquanto conceito, fundamento teórico, epistemológico e pragmático" (SILVA, 2015, p. 95).

$\mathrm{Na}$ Biblioteconomia e Ciência da Informação, a mediação foi concebida e apropriada recentemente, sendo amplamente estudada no âmbito dos equipamentos informacionais, compreendidos aqui como os ambientes e as unidades de informação. Enquanto objeto de estudo destas áreas, a mediação admite vários enfoques, dentre os quais merecem destaque, a mediação da informação, da leitura e da pesquisa. Diante desta breve categorização, é nosso propósito abordar neste artigo, apenas a mediação da informação.

À luz da teoria bibliográfica, observamos que a mediação da informação se realiza mais plenamente no esteio dos equipamentos informacionais, já que estes dispõem, por excelência, de todo o aparato estrutural e humano para promover atividades de mediação informacional e avaliar os resultados destas ações. Nestes ambientes, as iniciativas são, em sua maioria, conscientes, ou seja, propostas intencionalmente com o objetivo de aproximar o usuário das fontes de informação, promovendo o uso e a apropriação das informações dispostas nestes recursos. Todas estas ações, planejadas e realizadas nos ambientes de informação, em especial, nas bibliotecas, traduzem as transformações, sobretudo, ideológicas, pelas quais passam esses espaços, desafiando, diariamente, bibliotecários e demais profissionais que atuam nas unidades de informação, a rever seus valores, prioridades, posturas e conhecimentos (BATTISTELLA; SOUZA, 2013).

Contudo, a mediação da informação permite outras possibilidades de apropriação, uso e produção de informação. A construção de conhecimento, que representa uma das mais importantes consequências da mediação da informação, não se restringe ao consumo das fontes escritas. A construção do conhecimento também ocorre por meio da oralidade, permitindo a apropriação de informações que são transmitidas verbalmente.

A oralidade no processo de construção do conhecimento contempla a valorização do conhecimento de mundo que, segundo Paulo Freire, antecede a compreensão da palavra escrita. A oralidade está presente nas rotinas cotidianas, pois é o instrumento que viabiliza a comunicação, tão essencial às relações humanas. Trabalhar a oralidade implica em "identificar, refletir e utilizar a imensa riqueza e variedade de usos da língua na modalidade oral” (CAVALCANTE; MELO, 2007, p. 89). 
Ao expor oralmente uma informação, uma experiência ou uma lembrança, o sujeito apropria-se de conteúdos diversos, construindo significados e agregando saberes à sua audiência e a si próprio. Neste aspecto, a exposição oral também constitui a mediação da informação, visto que a mediação informacional compreende a organização, a própria mediação, o acesso, a recuperação, o uso e a apropriação da informação.

Considerando as potencialidades da oralidade para os estudos de mediação da informação, nos deparamos com o método da narrativa oral e história de vida, metodologias advindas da História Oral, que, por sua vez, é considerada um campo interdisciplinar, que se baseia na interatividade humana, contemplando as narrativas individuais (PERAZZO, 2015).

Através do aporte metodológico que a História Oral oferece, é possível identificar e compreender os processos mediacionais na perspectiva das narrativas orais e histórias de vida. Tomando então esta ideia, partimos da seguinte indagação: quais as possíveis relações entre a mediação da informação, a narrativa oral e a história de vida no âmbito do fazer bibliotecário? Assim, este ensaio tem por objetivo abordar as concepções de mediação da informação a partir do fazer bibliotecário, visando uma aproximação com as perspectivas da narrativa oral e história de vida.

Contudo, iniciaremos nossas reflexões buscando compreender, a priori, o próprio conceito de Mediação da Informação, já que, pensar a rotina das unidades de informação e do fazer bibliotecário pela sua ótica, tornou-se necessário e inevitável. Em decorrência da multiplicação dos estudos em torno da mediação, percebemos na literatura corrente, diferentes contornos acerca da sua definição. Assim, vislumbrando uma compreensão clara e ampla deste conceito, partiremos agora para as considerações conceituais de mediação.

\title{
2 MEDIAÇÃO DA INFORMAÇÃO: DELINEAMENTOS CONCEITUAIS
}

No sentido etimológico da palavra, Russ (1994, p. 180. apud MARTINS, 2014) conceitua mediação como:

\begin{abstract}
A palavra mediação vem do latim mediatione que designa intervenção humana entre duas partes, a ação de dividir em dois ou estar no meio, indicando ideias de interveniência, relação, conjugação, religação, ponte ou elo estabelecido nas relações humanas, por meio de um elemento mediador.
\end{abstract}

Na perspectiva teológica o legado deixado é de mediação como elo entre Deus e o homem, trazendo a ideia de intercessor. Na visão de Carvalho (2015), é possível encontrar na literatura vários aspectos ligados à mediação. A interseção e a reconciliação estão entre os sentidos primeiros e mais originais do termo: como termo jurídico no sentido de conciliação; cultural e interpretativa, a partir das experiências dos contextos vividos; e sociológicacomunicacional, sendo a linguagem seu maior sustentáculo. 
Porém na Ciência da Informação e Biblioteconomia esse conceito ganha uma ressignificação quando contempla a mediação como um processo onde alguém que guia, orienta, intermedeia, amplifica, organiza e desenha processos formativos, o que implica na ação de construção humana mais complexa (FARIAS, 2016).

Quando pensamos em mediação da informação, no âmbito da Biblioteconomia, imediatamente nos vem à mente a ação de servir de intermediário, ou seja, pensamos na interatividade entre bibliotecário e usuário. Entre os sentidos produzidos pelo senso comum, temos a ideia de mediação da informação associada, prioritariamente, à imagem de uma ponte, em que o bibliotecário seria a própria ponte, conduzindo o usuário à informação desejada.

Durante um longo período, esta concepção de mediação esteve internalizada nos profissionais da área e era reafirmada pelos estudiosos. Marco Antônio de Almeida (2007), por exemplo, é um dos autores que reconhece ter concebido a ideia de mediação como a prática de atendimento ao usuário, apenas. Mas a mediação da informação não se resume ao atendimento ao usuário. A mediação da informação envolve e determina todo o fazer do profissional da informação. Para Almeida Júnior (2009, p. 92), a mediação da informação é:

Toda ação de interferência, realizada pelo profissional da informação, direta ou indireta, consciente ou inconsciente, singular ou plural, individual ou coletiva, que propicie a apropriação da informação que satisfaça, plena ou parcialmente, uma necessidade informacional.

Aprimorando este conceito, Jonathas Silva (2015, p. 103) defende que a mediação da informação é:

\begin{abstract}
um conjunto de práticas construtivas de intervenções e interferências regidas por intencionalidades, normas/regras, correntes teórico-ideológicas e crenças concebidas pelo profissional da informação em interação com os usuários no âmbito de suas realidades cotidianas e experienciais, indicando procedimentos singulares, coletivos e/ou plurais de acesso e uso da informação, estimulando à apreensão e apropriação para satisfação de necessidades de informação.
\end{abstract}

Nos dois conceitos apresentados, nós podemos perceber uma palavra em forte evidência: interferência. A mediação da informação é uma ação de interferência, mas por quê? Bem, o bibliotecário, antes de tudo, é um ser social e político. Dotado de historicidade, crenças e valores. E todos estes elementos, inevitavelmente, irão se refletir em sua atuação profissional. Mas ao contrário do que se possa pensar, essa interferência não é prejudicial, pelo contrário, ela é vista como algo positivo, uma tentativa de abandonar a neutralidade técnica e conduzir a construção de um perfil profissional em que o bibliotecário esteja mais engajado nas causas da sua comunidade usuária.

Diante do que fora exposto até aqui, podemos perceber que a mediação da informação não é algo estático como pressupõe a ideia da ponte, mas uma construção social que envolve bibliotecários e usuários, resultando na apropriação da informação pelo usuário. Percebemos

\begin{tabular}{|c|c|c|c|c|c|}
\hline (C) RDBCI: Rev. Digit. Bibliotecon. Cienc. Inf. & Campinas, SP & v.16 & n. 2 & p. $461-482$ & maio/ago. 2018 \\
\hline
\end{tabular}


também a pluralidade conceitual em torno da concepção de mediação. Contudo, nos estudos sobre a mediação da informação, aplicáveis aos ambientes informacionais, podemos inferir que existem alguns tipos ou variedades de mediação. Para fins de delimitação conceitual, iremos nos basear na tipologia mediacional segundo a perspectiva dos autores Almeida Júnior e Jonathas Silva.

De acordo com Almeida Júnior (2009, p. 92), a mediação da informação pode ser classificada como implícita e explícita. Estando presente nos fazeres do profissional da informação, o referido autor identifica que:

[...] em algumas ações, no entanto, a mediação está presente de forma implícita, muito embora dirigindo e norteando todas as atividades ali desenvolvidas. $\mathrm{O}$ armazenamento de informações é alimentado a partir de interesses e demandas dos usuários. A política de seleção, amplamente discutida no desenvolvimento de coleções, tem o usuário final como base de sustentação. O mesmo se dá com os trabalhos de processamento das informações: têm suas ações voltadas para a recuperação de informações que atendam e satisfaçam necessidades dos usuários.

Todo o fazer das atividades realizadas na biblioteca ou centros de informação devem ter como objetivo principal o atendimento às necessidades informacionais dos seus usuários. O profissional da informação deve buscar da melhor maneira possível, intermediar ou interferir no uso e acesso a informação.

Conforme Almeida Júnior (2009, p. 92), “a mediação implícita, ocorre nos espaços dos equipamentos informacionais em que as ações são desenvolvidas sem a presença física e imediata dos usuários." Dessa forma, a mediação implícita se caracteriza como aquela onde só existe a ação do profissional da informação, desenvolvendo um serviço interno, sendo estes exemplificados como formação e desenvolvimento de coleções, processos técnicos (catalogação e classificação), preservação (conservação e restauração), e trabalhos realizados na biblioteca digital, ou seja, no instante antes da informação estar disponível para consulta.

Segundo Santos Neto (2014, p. 92),

A mediação implícita da informação, uma prática tão presente no cotidiano do bibliotecário, é ainda pouco discutida. Outra preocupação é a questão do bibliotecário não perceber a mediação em momentos distintos, momentos estes que necessitam da interferência desse profissional.

Geralmente o bibliotecário nem percebe quando está realizando a mediação implícita, por ser uma atividade onde não se vê a interferência direta do usuário final da informação, não sendo por isso, menos importante que qualquer outra atividade desenvolvida.

Já, acerca da mediação explícita da informação, Almeida Júnior (2009, p. 93), afirma:

A mediação explícita, por seu lado, ocorre nos espaços em que a presença do usuário é inevitável, é condição sine qua non para sua existência, mesmo que tal 
presença não seja física, como, por exemplo, nos acessos à distância em que não é solicitada a interferência do profissional da informação.

Como exemplos práticos de mediação explícita da informação nos contextos informacionais, podemos citar a mediação da informação para a leitura, para a pesquisa, no contexto dos serviços prestados, sendo o serviço de referência um exemplo de serviço prestado, bem como, o uso das tecnologias de informação e de comunicação.

Partindo do entendimento do autor Silva (2015, p. 105),

Pode-se assim, identificar e explicitar alguns tipos de mediação passíveis de serem aplicados principalmente em centros de informação considerando que toda e qualquer mediação é um construto social, crítico e interacionista e envolve contextos coletivos e plurais:

a) mediação técnica da informação - concerne as ações de organização, representação da informação envidadas pelo profissional da informação estimulando o uso da informação, seja em ambiente físico ou virtual. Por exemplo, a elaboração de catálogos, interação por e-mail e/ou redes sociais do acervo do centro de informação, entre outros.

b) a mediação pedagógica da informação - consiste na condução dos procedimentos e heurísticas a serem utilizadas no processo de mediação. Para tanto, é fundamental um olhar constante nos estudos de usuários contemplando questões relativas ao uso do acervo, das condições tecnológicas, do serviço, das questões de pessoal e avaliação da atuação do centro de informação de forma geral buscando uma aproximação com a comunidade, assim como promovendo autonomia para que o usuário tenha condições de escolha para apreensão e apropriação da informação; c) mediação institucional da informação - está relacionada aos procedimentos de como o profissional da informação irá buscar recursos (financeiros, pessoais, equipamentos, acervo, instrumentos tecnológicos, etc.), seja dentro ou fora da instituição que o centro de informação está inserido para concretizar suas ações e interferências, assim como promover sua sustentabilidade. (Grifo nosso).

Silva (2015) discorre sobre três tipos de mediação da informação, sendo estas descritas como mediação técnica da informação, mediação pedagógica da informação e mediação institucional da informação.

Na mediação técnica, o profissional da informação utiliza procedimentos que irão auxiliar no tratamento e disponibilização da informação para posterior acesso e uso. Quando se pensa na mediação pedagógica, está se referindo ao estudo da comunidade, criando métodos que promovam a autonomia do usuário da informação, enquanto a mediação institucional, prevê a articulação que o profissional deverá desenvolver para obter recursos para a melhoria dos serviços e produtos oferecidos pelo ambiente informacional.

Por conseguinte, Silva (2015, p. 105), considera a mediação da informação como sendo,

Observa-se, desse modo, que a mediação constitui um papel central nos estudos em Ciência da Informação, pois além de conferir novas aplicabilidades e percepções conceituais para este Campo, contribui de forma efetiva para pensar a atuação dos centros de informação, assim como está vinculada a fatores diversos da Ciência da 
informação, como aspectos teórico-epistemológicos, tecnologia, gestão, serviços, estudos de usuários, entre outros assuntos da área.

Contudo, podemos afirmar que a mediação da informação é construída socialmente a partir das relações interacionais, das ações implícitas e explícitas que estão envolvidas no processo.

A mediação da informação abrange, pois, todo o fazer profissional do bibliotecário, alcançando todos os setores de sua atuação, desde a seleção de recursos bibliográficos até a disseminação da informação. Isso porque todos os esforços empreendidos pelo bibliotecário, são direcionados e norteados a partir dos interesses e demandas dos usuários. Todo o trabalho do bibliotecário está voltado para o atendimento das necessidades informacionais do seu público e isso é mediação da informação. Em suma, qualquer tipologia de mediação da informação utilizada, consiste em verificar novas formas de acesso e uso da informação, promovendo sempre um novo olhar para as práticas informacionais, visando à satisfação dos usuários através de serviços prestados.

Dada a apresentação dos conceitos de mediação da informação, seguiremos agora para a sua aplicação no fazer profissional do bibliotecário. Esta ordem de exposição das ideias, justifica-se no pressuposto de que a atuação do bibliotecário deve ser o retrato de uma teoria bem internalizada (SANCHES; RIO, 2010) e, assim sendo, o conhecimento das percepções conceituais acerca de um determinado tema, contribui para a formação de competências e habilidades que promoverão uma prática profissional mais consistente e consciente dos propósitos e resultados que se espera alcançar. A seguir, ressaltaremos como o bibliotecário deve atuar com mediação da informação.

\section{O BIBLIOTECÁRIO E O SEU FAZER MEDIACIONAL}

A sociedade contemporânea é chamada de Sociedade do Conhecimento exatamente por enfrentar um fluxo contínuo e infindo de informações geradas e transpostas para além dos impressos, alcançando infinitos espaços. Nesta perspectiva, notamos a necessidade de utilizar estratégias de mediação da informação, reunindo as condições necessárias para que os leitores/usuários sejam capazes de consumir, produzir e disseminar informação.

A mudança de comportamento pela qual passou a sociedade, também repercutiu nas bibliotecas, que progressivamente, abandonam a concepção de biblioteca como ambiente fechado e inacessível, em que a presença do leitor era inconcebível, para favorecer o desenvolvimento de novas concepções e paradigmas aplicáveis a estes espaços, que ora incorporam a ideologia do livre acesso, procurando responder às necessidades informacionais de seu público e oferecer um ambiente dinâmico em que se possa conjugar informação e cultura e, o bibliotecário, possa exercer "o papel de filtro que se interpõe entre a torrente de livros e o homem" (FONSECA, 2007, p. 93). 
Este novo espaço, que se apresenta como recurso pedagógico eficiente na construção de conhecimento, assume atualmente outros papéis que vão além da guarda de materiais. E dentro deste contexto, o bibliotecário, entendido também como profissional da informação, incorpora uma nova atribuição: a de planejar e realizar ações que promovam o consumo das fontes, a apropriação de conteúdos e a produção de novas informações. Desta forma, o bibliotecário desempenha um papel ativo, configurando-se como agente de mudanças sociais. Acerca destas novas responsabilidades, que evidenciam o caráter mediador do bibliotecário, Sanches e Rio (2010, p. 104) afirmam:

E para que as características próprias desse papel mediador do bibliotecário sejam exploradas em toda sua potencialidade é de extrema importância que o bibliotecário perceba e internalize o seu papel transformador dentro do Serviço de Referência e Informação. Para que tal contribuição se concretize se faz imprescindível o compromisso e a responsabilidade do profissional em participar do processo de construção de conhecimento político e histórico de sua comunidade usuária. Mas para que isso ocorra o profissional bibliotecário em primeiro lugar deve reconhecer sua identidade profissional e também se reconhecer como parte integrante daquela comunidade.

A imagem do profissional da informação como o guardião do saber, priorizando os livros em detrimento dos usuários, retratada por Umberto Eco em sua obra $O$ nome da Rosa, é substituída, paulatinamente, pela imagem do mediador de informação e conhecimento a imaginar modos mais participativos e horizontais de acesso à informação (RODRIGUES 2017).

Neste aspecto, a atuação do bibliotecário, com ênfase na mediação, passou a ser substancial nos ambientes de informação, pois tão importante quanto constituir e disponibilizar acervos diversificados, é viabilizar o uso e a apropriação dos conteúdos dispostos nestes recursos. Contudo, a mediação da informação propõe que o fazer profissional do bibliotecário esteja sempre integrado com a comunidade a qual ela se destina, se utilizando da técnica para promover espaços de apropriação da informação (SANCHES; RIO, 2010).

Numa perspectiva pragmática, podemos afirmar que são inúmeras as ações que o bibliotecário pode desenvolver enquanto mediador da informação. Assim, buscando especificar estas ações, elaboramos, a partir das concepções de Silva (2017), o quadro abaixo, que mostra os diversos setores em que se aplica a mediação da informação.

Quadro 1 - As práticas de atuação profissional do bibliotecário na perspectiva da mediação da informação

\begin{tabular}{|l|l|}
\hline Tipo de ação & Descrição da ação sob o enfoque da mediação \\
\hline & $\begin{array}{l}\text { Envolve práticas informacionais de cunho pedagógico } \\
\text { (mediação explícita) e práticas informacionais de }\end{array}$ \\
\hline
\end{tabular}

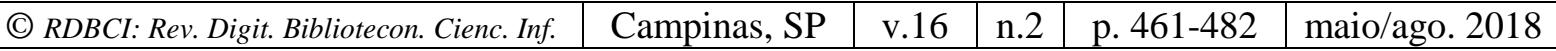




\begin{tabular}{|c|c|}
\hline Serviços de Informação & $\begin{array}{l}\text { natureza técnica (mediação implícita) oferecidas à } \\
\text { comunidade. Entre os serviços de cunho pedagógico } \\
\text { estão: Serviço de Referência, Informação Utilitária, } \\
\text { Disseminação Seletiva da Informação e Serviço de } \\
\text { Alerta. Dentre os serviços informacionais de ordem } \\
\text { técnica, encontram-se: Organização, Representação, } \\
\text { Sinalização do Acervo, Consulta, Empréstimo e } \\
\text { Renovação de Materiais. }\end{array}$ \\
\hline Estudo de Usuários & $\begin{array}{l}\text { Propõe um diálogo formal e/ou informal com a } \\
\text { comunidade usuária, a fim de conhecer seus interesses } \\
\text { e demandas informacionais, que, por sua vez, } \\
\text { nortearão os trabalhos de composição do acervo e } \\
\text { proposição dos serviços a serem disponibilizados pela } \\
\text { unidade de informação. Tudo isto, objetivando } \\
\text { satisfazer e impactar a comunidade usuária, ações que } \\
\text { traduzem os propósitos da mediação da informação. }\end{array}$ \\
\hline Dinamização do Acervo & $\begin{array}{l}\text { Relaciona-se com a Política de Desenvolvimento de } \\
\text { Coleções, Serviços de Informação e Estudo de } \\
\text { Usuários. A configuração do acervo deve estar em } \\
\text { conformidade com as demandas informacionais da } \\
\text { comunidade atendida, de modo a favorecer o acesso e } \\
\text { uso das fontes para a posterior apropriação e produção } \\
\text { de informação pelos sujeitos usuários, etapa que } \\
\text { constitui o principal objetivo da mediação da } \\
\text { informação. }\end{array}$ \\
\hline Uso de Tecnologias & $\begin{array}{l}\text { A disponibilização de suportes/ambientes digitais } \\
\text { favorece a identificação, o acesso e uso das fontes } \\
\text { informacionais, bem como, o conhecimento da } \\
\text { diversidade informacional existente, multiplicando as } \\
\text { possibilidades de apropriação da informação. }\end{array}$ \\
\hline Formação de Competências & $\begin{array}{l}\text { A mediação da informação implica no } \\
\text { desenvolvimento de competências e habilidades a } \\
\text { serem praticadas por profissionais e comunidade } \\
\text { usuária. Estas competências e habilidades possibilitam } \\
\text { a apropriação e produção de informação, construção de } \\
\text { novos conhecimentos, aprendizagem e progresso } \\
\text { instrucional do sujeito. }\end{array}$ \\
\hline \multirow[t]{2}{*}{ Ações Culturais } & $\begin{array}{l}\text { Refere-se às práticas de mediação cultural, } \\
\text { contemplando as demandas e interesses da } \\
\text { comunidade usuária. }\end{array}$ \\
\hline & Trata-se da capacitação/instrução dos sujeitos usuários, \\
\hline
\end{tabular}




\begin{tabular}{|l|l|}
\hline Educação de Usuários & $\begin{array}{l}\text { fornecendo-lhes as condições necessárias para a } \\
\text { manipulação dos recursos oferecidos pela unidade de } \\
\text { informação, contribuindo para o empoderamento do } \\
\text { usuário frente aos recursos informacionais disponíveis } \\
\text { e tornando-os autônomos no processo de apropriação } \\
\text { da informação e no seu próprio processo de } \\
\text { aprendizagem. }\end{array}$ \\
\hline Preservação da Memória & $\begin{array}{l}\text { Consiste em manter acessível as informações } \\
\text { produzidas em outrora que subsidiarão novos estudos, } \\
\text { a produção e propagação de novas informações, num } \\
\text { ciclo contínuo de construção de conhecimentos. }\end{array}$ \\
\hline
\end{tabular}

Fonte: As autoras

Contudo, é possível afirmar que a mediação da informação se constitui como um programa de ações e se relaciona com todos os campos de atuação profissional do bibliotecário. Neste processo, que reúne diversas práticas profissionais, a mediação da informação abre espaço para um comportamento protagonista do usuário, em que se considera seu conhecimento prévio, suas habilidades cognitivas para apreender, transformar e construir novos conhecimentos. Assim, participando ativa e coletivamente do processo de mediação da informação, a mediação deve ser construída não apenas para o usuário, mas com o usuário, ocorrendo numa perspectiva de diálogo e ação recíproca (SILVA, 2015).

A partir das ações de mediação da informação, o bibliotecário proporciona a valorização e transformação do espaço sociocultural da comunidade. Oferece à comunidade usuária recursos cognitivos que possibilitarão a reflexão sobre os valores formadores de sua conduta em meio à sociedade, bem como, a autonomia do usuário no seu processo de construção do conhecimento (SANCHES; RIO, 2010).

Após estas considerações, adiante, estabeleceremos as relações entre mediação da informação, narrativas orais e histórias de vida.

\section{NARRATIVAS ORAIS, HISTÓRIAS DE VIDA E MEDIAÇÃO DA INFORMAÇÃO: RELAÇÕES DIALOGAIS}

No mundo contemporâneo, vivenciamos a hegemonia da escrita sobre a oralidade, seja nas instituições de educação formal, como escolas, universidades e unidades de informação; nos meios de comunicação ou mesmo, na vida cotidiana. A escrita é frequentemente sobreposta à oralidade, que por sua vez, é desprezada e relegada a uma existência inferior, o que evidencia a tensão subsistente entre estas duas formas de construção de sentidos (HAVELOCK, 1996). Mas, adquirir informação, construir conhecimento, perpetuar crenças, valores e tradições também é perfeitamente possível através da oralidade, visto que ela

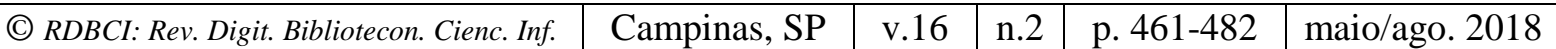


consiste numa composição de pensamentos (BATTISTELLA; SOUZA, 2013), que utiliza a fluidez e a dinâmica da voz.

Nos primórdios da humanidade, mais precisamente, nas sociedades sem escrita, a comunicação e toda a transmissão do legado informacional e cultural de um povo, se realizava mediante a oralidade, base da construção da história humana. Daí emerge a importância da memória, como instrumento essencial para a preservação e propagação do conhecimento produzido por um povo.

Assim, o ato de narrar é intrínseco à condição humana. A fala é a primeira habilidade comunicativa apreendida pelo homem e a característica que o diferencia dos demais seres vivos. Roland Barthes afirmava que a humanidade narra como respira: naturalmente, sendo a oralidade, uma capacidade meramente espontânea do ser humano, visto que ela está impregnada em nosso dia a dia. Ratificando esta ideia de fluidez da oralidade, Ong (1998, p. 16) afirma que "a escrita não pode prescindir da oralidade, mas ao contrário, a expressão oral pode existir - e na maioria das vezes existiu - sem qualquer escrita”. Ampliando estas acepções, o autor ainda declara:

[...] a despeito dos mundos maravilhosos que a escrita abre, a palavra falada ainda subsiste e vive. Todos os textos escritos devem, de algum modo, estar direta ou indiretamente relacionados ao mundo sonoro, habitat natural da linguagem, para comunicar seus significados. 'Ler' um texto significa convertê-lo em som, em voz alta ou na imaginação, sílaba por sílaba na leitura lenta ou de modo superficial na leitura rápida, comum a culturas de alta tecnologia (ONG, 1998, p. 16).

Com esta declaração, o autor afirma que, embora a língua escrita concentre mais expressividade e seja mais valorizada do que a língua falada no âmbito da educação formal, da transmissão de informações e da preservação da memória histórica, ela, a língua escrita, subsiste numa relação de interdependência com a língua falada, sendo esta última anterior àquela e que assume a missão de dar vida à palavra escrita. Dialogando com este pensamento, Medeiros (2007, p. 70) nos diz:

[...] como indicam, por exemplo, A Ilíada e a Odisséia, surgidas como canto entoado por várias gerações até serem fixadas pela escrita. Assim, as relações entre voz e letra, oralidade e escrita foram e são tão íntimas quanto complexas e problemáticas, qualidades que se intensificam em função das novas formas de oralidade surgidas com as constantes transformações tecnológicas.

É possível perceber a conexão existente entre oralidade e escrita, embora oralidade e escrita não possam ser analisadas sob os mesmos critérios. A oralidade permite o uso de recursos linguísticos não apreciados na escrita, proporcionando mais leveza e informalidade ao discurso, evidenciando também a subjetividade de quem fala. Já a escrita, por se tratar de uma estrutura fixa e estática, prima por uma maior objetividade e formalidade.

As contribuições da oralidade no processo de aprendizagem e construção do conhecimento se efetivam principalmente em função da língua na modalidade falada, que se \begin{tabular}{l|l|l|l|l|l}
\hline C RDBCI: Rev. Digit. Bibliotecon. Cienc. Inf. & Campinas, SP & v.16 & n.2 & p. 461-482 & maio/ago. 2018 \\
\hline
\end{tabular} 
aproxima das experiências, saberes e domínios do sujeito, diferentemente do que ocorre com o texto escrito, que muitas vezes apresenta vocábulos com os quais o sujeito não está familiarizado (MEDEIROS, 2007), dificultando a compreensão e, consequentemente, o processo de apropriação da informação. Nesta perspectiva, a oralidade aborda novas possibilidades de aprendizagem, capacitando o sujeito para receber informações e interagir socialmente (SOUSA; LIMA, 2016), promovendo assim, uma participação mais ativa desse sujeito em seu contex to social, enriquecendo, contudo, sua experiência humana.

Autores como Medeiros (2007), Havelock (1996) e Bajard (2001) defendem a importância de inserir a oralidade na formação escolar desde as séries iniciais, o que minimizaria as distâncias entre língua falada e língua escrita, já que a oralidade, por meio das narrativas, recitação de versos ou leitura em voz alta dos textos, captura melhor a atenção do leitor/ouvinte, capacitando-o para absorver, interpretar e apropriar-se, mais eficazmente, das informações ali presentes.

Dentro deste escopo da oralidade, encontra-se a História Oral, que do ponto de vista metodológico, constitui uma técnica de produção, coleta e análise de fontes de pesquisa (PERAZZO, 2015). Enfatizando este conceito, Alberti (1989, p.1-3) afirma que a História Oral é:

É um método de pesquisa (histórica, antropológica, sociológica, etc.) que privilegia a realização de entrevistas com pessoas que participam de, ou testemunharam, acontecimentos, conjunturas, visões de mundo, como forma de se aproximar do objeto de estudo. Trata-se de procurar compreender a sociedade através do indivíduo que nela viveu; de estabelecer relações entre o geral e o particular através da análise comparativa de diferentes versões e testemunhos.

A História Oral tem como alicerce a narrativa oral, sem a qual um acontecimento, um fato ou uma situação vivida pelo sujeito não poderia torna-se conhecida (ALBERTI, 2003). Aqui, as narrativas orais são tomadas como discursos produzidos pelos sujeitos, que por meio da sua oralidade, expressam sua lembrança e seu conhecimento (PERAZZO, 2015), acionando sua capacidade cognitiva e psíquica de interação com o meio no qual estão inseridos.

As narrativas orais se fazem presente em todos os campos da atuação humana e favorecem o compartilhamento de saberes e experiências de um indivíduo ou de um grupo. Através desta prática, o sujeito ressignifica e atualiza suas percepções, constrói e transmite conhecimento.

Ao narrar suas experiências e expressar seus conhecimentos, o sujeito transforma suas vivências e saberes em linguagem, selecionando e organizando as informações de acordo com determinado sentido (ALBERTI, 2003). Em função deste seu caráter, as narrativas orais permitem reconstituir a crônica do cotidiano (BOSI, 2003). Ainda segundo Bosi, “[...] os velhos, as mulheres, os negros, os trabalhadores manuais, camadas da população excluídas da

\begin{tabular}{l|l|l|} 
v.16 & n.2 & p. 461-482
\end{tabular}

maio/ago. 2018 
história ensinada na escola, tomam a palavra" (BOSI, 2003, p. 15). Ou seja, as narrativas orais possibilitam desbravar um universo inexplorado de informações, repleto de detalhes desconhecidos e que nos podem ser revelado a partir deste instrumento.

Dentro do amplo quadro da História Oral, que tem como base as narrativas, está a História de Vida, definida por Queiroz (1988, p. 20-21) como sendo:

\begin{abstract}
o relato de um narrador sobre sua existência através do tempo, tentando reconstituir os acontecimentos que vivenciou e transmitir a experiência que adquiriu. Narrativa linear e individual dos acontecimentos que nele considera significativos, através dela se delineiam as relações com os membros de seu grupo, de sua sociedade global, que cabe ao pesquisador desvendar. Desta forma, o interesse deste último está em captar algo que ultrapassa o caráter individual do que é transmitido e que se insere nas coletividades a que o narrador pertence. [...] Este (o entrevistado) é quem determina o que é relevante ou não narrar, ele é quem detém o fio condutor.
\end{abstract}

As histórias de vida representam a melhor maneira de compreender a cultura e o passado do "lado de dentro", como um conjunto vivo, regido pela harmonia interna, não como um conjunto arbitrário de costumes e instituições, cuja realidade é apenas percebida (FERNANDES; LOUREIRO, 2009).

No trabalho com histórias de vida, o sujeito é colocado em ênfase, sendo valorizada sua concepção de mundo e sua dimensão subjetiva (PERAZZO, 2015).

Este interesse da ciência, que desloca para sujeito e suas relações, o foco investigativo, se deve, a priori, ao entendimento de que todo indivíduo é, antes de tudo, um ser social. E assim sendo, cada sujeito traz consigo um arcabouço de memórias, conhecimentos e informações que se misturam à história do grupo no qual ele está inserido. Deste modo, em toda fala de um sujeito há algo que se relaciona, direta ou indiretamente, com os "aspectos importantes de sua sociedade e de seu grupo, comportamentos e técnicas, valores e ideologias podem ser apanhados através de sua história" (QUEIROZ, 1988, p. 28). Logo, cada sujeito representa uma potencial e rica fonte de dados para a ciência em geral.

Diante do exposto, é possível perceber as diferenças que envolvem os conceitos de História Oral, Narrativas Orais e Histórias de Vida, que, embora se complementem, representam ideias distintas. Estes esclarecimentos conceituais e epistemológicos se tornam necessários visto que na literatura corrente há uma carência distintiva entre tais termos, sendo estes comumente tratados como expressões sinônimas.

Neste momento, aproximamos as narrativas orais e as histórias de vida do campo de estudos sobre mediação da informação, assinalando que as ideias expostas a seguir, são fruto de reflexões próprias, possibilitadas pelas discussões ocorridas em sala de aula, durante a disciplina Mediação da Informação, ofertada na grade curricular do Mestrado Profissional em Biblioteconomia, da Universidade Federal do Cariri. Tais reflexões partem ainda da análise da literatura especializada que versa sobre a temática em foco. As relações dialogais \begin{tabular}{l|l|l|l|l|l}
\hline (C) RDBCI: Rev. Digit. Bibliotecon. Cienc. Inf. & Campinas, SP & v.16 & n.2 & p. 461-482 & maio/ago. 2018 \\
\hline
\end{tabular} 
propostas neste trabalho são pioneiras e originam-se de nossas inquietações acerca das potencialidades mediacionais identificadas na oralidade, não havendo na literatura, estudos anteriores que permeassem estas linhas de pensamento.

Contudo, em meio ao debate teórico que circunda as concepções de mediação da informação, compreendemos que esta ocorre plenamente quando há a apropriação da informação, contribuindo para a produção de um novo conhecimento ou a afirmação de conhecimentos ainda não consolidados. Esta apropriação, segundo Chartier (2003), é ação afirmativa, é invenção e criação e não simples recepção mecânica e automática de sinais e mensagens. Em outras palavras, a apropriação é o fenômeno de construção do conhecimento.

Partindo deste pressuposto, quando um sujeito discorre sobre determinado tema, ou mesmo narra sua própria história, ele está exercendo práticas de socialização da informação, tornando acessível e consumível o legado informacional inerente a ele. Por conseguinte, as mensagens e informações emitidas por este sujeito, podem apresentar-se de maneira extremamente relevante para a sua audiência, que por fim, pode vir a apropriar-se delas, utilizando-as com a finalidade de agregar novas informações ao seu repertório, ou proceder ao processo de construção de conhecimento. Assim, descortina-se o caráter mediacional das narrativas orais e histórias de vida.

A mediação realizada nesta perspectiva também se fundamenta como interferência premeditada ou espontânea de um mediador, que pode ser o próprio narrador ou um personagem externo à narrativa, cujo objetivo é disseminar as informações das quais detém.

Neste sentido, Santos Neto e Almeida Júnior (2015, p. 364), citando Bicheri (2008), declara que o mediador:

[...] pode ser um professor, um padre, um pastor, um escritor, um jornalista, um apresentador de televisão ou rádio, um bibliotecário, um crítico de cinema, entre outros. Cada mediador tem sua devida importância e um papel a ser desempenhado na sociedade.

Logo, é possível constatar que a mediação da informação está presente nos mais diversos contextos. E onde ela está, estará também a figura do mediador.

O bibliotecário, pela própria natureza de sua atuação, a lidar com os recursos, informacionais e ambientais, potencialmente favoráveis à mediação da informação, está apto a assumir o papel de mediador da informação, sem que esta mediação se restrinja às fontes escritas, cabendo abrir espaço para contemplar outras possibilidades, e assim, tornar-se um efetivo mediador também na perspectiva das narrativas orais. Para isso, o bibliotecário pode desenvolver ações, dentro ou fora dos equipamentos informacionais, elegendo temáticas, atuais, utilitárias ou quaisquer outras que viessem a interessar sua comunidade usuária, estruturando-as para serem disseminadas e debatidas oralmente. 
Bortolin (2010), afirma que não é somente o público infantil que aprecia a narrativa oral, mas também o fazem adolescentes e adultos. A socialização de temas pertinentes ao cotidiano das pessoas, trazidos sob a narrativa de um entendedor do assunto, podendo acompanhar ou não relatos de histórias de vida, como forma de exemplificar o tema, oportuniza a quem escuta, refletir sobre sua própria condição, seus objetivos e os caminhos que pode traçar para alcançá-los, transformando, assim, sua própria realidade. Com isso, a mediação da informação atinge o seu clímax, o seu maior propósito: impactar as pessoas.

Reportamo-nos, neste instante, a uma prática concreta de mediação da informação, realizada por um professor amigo, na escola em que atua, cuja temática da ação abordaria a violência contra a mulher. Segundo nosso personagem,

\begin{abstract}
O evento foi pensado num momento de luta política, em que os movimentos sociais posicionavam-se contra as reformas propostas pelo governo federal, deliberadas em 2016. Os alunos do IFPI - Campus Teresina Zona Sul se instalaram nas dependências da escola como forma de resistência às mudanças que se anunciavam e que afetariam as minorias, sem distinção. Neste contexto, um ciclo de palestras foi idealizado, abordando temas transversais, cujo objetivo era discutir alguns dos problemas atuais da sociedade, tais como: a reforma da previdência, a PEC do teto dos gastos, a reforma do Ensino Médio, a participação da mulher na sociedade e inevitavelmente, a violência, física e simbólica sofrida por esta parcela da população. Sobre esta última temática, pensada para ser dialogada e não meramente expositiva, e, tratando-se de uma realidade tão próxima do cotidiano das pessoas, houve uma maior interação por parte da plateia, composta em sua maioria por mulheres. Em um dado momento da roda de conversa, uma outra professora, que também participava do evento, apresentou fragmentos de sua história de vida, ao relatar também ter sido vítima de violência doméstica, praticada por seu então companheiro, o que causou surpresa em muitos que ali estavam. Com a voz embargada e os olhos marejados, a professora compartilhou memórias deste momento devastador, encerrando sua fala estimulando as mulheres que lhe ouviam a não silenciar e reagir diante destas amargas experiências (SÁ, depoimento oral, 2017) ${ }^{1}$.
\end{abstract}

Percebemos nesta citação, constructo da narração oral do professor mencionado, que a mediação da informação se faz presente na exposição oral do narrador, na ação de quem propõe a atividade, neste caso específico, o professor, bem como, nos relatos de história de vida, possibilitando a ampliação do repertório informacional de quem escuta, assim como também, a apropriação das informações ali transmitidas para vias de reflexão e transformação da realidade.

Se o depoimento pessoal da professora acerca da violência doméstica sofrida, provocou o encorajamento de alguma outra mulher da plateia, que, ocasionalmente, pudesse estar vivenciando situação semelhante, não podemos afirmar. Mas é exatamente assim que se

\footnotetext{
${ }^{1}$ Depoimento oral proferido pelo professor de sociologia do Instituto Federal do Piauí - Campus Teresina Zona Sul, José Marcílio de Sá, concedido a uma das autoras deste artigo, Ana Cristina Guimarães Carvalho, em dezembro de 2017.
} 
dá a mediação da informação: constrói os mecanismos para o uso e a apropriação dessa informação, mas as ações efetivas de uso e apropriação da informação não são passíveis de constatação. A mediação da informação deve ser pensada para causar impacto na comunidade a qual ela se dirige, entretanto, os seus efeitos somente são possíveis conhecer dado o feedback da comunidade.

Neste sentido, o bibliotecário assume a atribuição de mediador da informação oral quando promove ações dessa natureza, aproximando o sujeito, a informação e a oralidade, pois:

Outra forma na tentativa de romper com toda a estrutura de dominação informacional é o emprego, o uso de todo e qualquer suporte que contenha potenciais informações e não exclusivamente aqueles que empregam o texto escrito (ALMEIDA JÚNIOR, 2004, p. 214).

Compartilhando deste mesmo entendimento, Silva (2015, p. 96) afirma que é urgente "a necessidade de se pensar instrumentos que valorizem a consistência do pensamento humano e a construção de conhecimento. Um desses instrumentos é a mediação [...]". Neste aspecto, a mediação da informação toma o sujeito como partícipe do processo mediacional, dado que, se considera o conhecimento prévio deste sujeito, suas habilidades cognitivas para apreender, transformar e construir novos conhecimentos. Assim, participando ativa e coletivamente do processo de mediação da informação, a mediação clama ser construída não apenas para o sujeito, mas com o sujeito, ocorrendo numa perspectiva de diálogo e ação recíproca (SILVA, 2015).

No contexto das tipologias mediacionais, a mediação da informação exercida sob o prisma das narrativas orais e histórias de vida se insere na mediação explícita, segundo a classificação de Almeida Júnior, ou na mediação pedagógica, conforme terminologia adotada por Jonathas Silva, posto que, a oralidade lida com a interatividade humana, com o contato direto e presencial entre quem narra e quem escuta, quem propaga informação e quem as absorve, lida com a presença imediata do sujeito, característica fundamental na mediação explícita ou pedagógica. Assim, as relações entre mediação e narrativa oral e história de vida estão situadas em uma perspectiva de cotidiano social (apresentando relações com o dia-a-dia das pessoas); construção do conhecimento; de aplicação (mediação explícita ou pedagógica) e envolvendo os aspectos sociais e intersubjetivos.

Finalmente, reiteramos que a mediação da informação subsiste em variadas conjunturas, sendo viavelmente aplicável ao contexto das narrativas orais e histórias de vida, em virtude do aspecto social e intersubjetivo que envolve a disseminação, apropriação e construção do conhecimento, presentes nestes três fenômenos. Do mesmo modo, ressaltamos que à medida em que o paradigma pós-custodial se fortalece e alcança consistência, as práticas de mediação da informação se tornam essenciais na atuação profissional do bibliotecário, conduzindo-o a repensar seu comportamento profissional com vistas a exercer uma mediação planejada, efetiva e transformadora. 


\section{CONSIDERAÇÕES FINAIS}

O sujeito e a informação são elementos fundamentais para a compreensão dos processos mediacionais e sua relação com as diversas práticas orais (PERAZZO, 2015). Tais práticas assumem um importante papel na aprendizagem do ser humano, constituindo-se como um processo básico no qual o indivíduo é capaz de receber informações e interagir socialmente (SOUSA; LIMA, 2016).

Das práticas informacionais surge a mediação documentada pelos saberes que a alicerçam. Logo, a produção, apropriação e o processo de significação da informação não podem ocorrer esvaziados das dimensões histórica, social e cultural do cotidiano dos sujeitos (CAVALCANTE, 2015).

Assim, buscou-se explicitar neste estudo, a relação do bibliotecário com o seu fazer mediacional, trazendo para a discussão a importância de um desempenho mais ativo deste profissional que, no seu fazer mediacional, não deve se restringir a promover o acesso e uso das fontes escritas, mas considerar a potencialidade das fontes orais para o processo de apropriação e construção do conhecimento.

Diante da multiplicidade de empregos e concepções acerca da mediação de informação, procuramos conceituar e delimitar a tipologia do tema em questão, de acordo com os autores citados, visando uma fundamentação precisa e uma melhor exposição das nuances que permeiam a mediação da informação.

Podemos perceber, portanto, que mediação no campo da Biblioteconomia e Ciência da Informação não se reduz a um ato de intermediação, mas envolve todas as ações que podem ser realizadas dentro e fora de um ambiente de informação com base em elementos como a cultura, educação e informação desencadeando transformações na vida da comunidade, assim também como a vida do mediador.

A mediação da informação é um procedimento afirmativo e interativo, e preocupa-se não somente com a disponibilização de conteúdos para a comunidade de sujeitos a quem ela se destina, mas favorece também a internalização e construção de conhecimento, a partir da apropriação de informação. Para isso, há que se considerar a necessidade de informação a começar da necessidade social e tornar o sujeito, um partícipe do processo mediacional.

Compreendemos ainda que, embora a biblioteca tenha sido, inicialmente, pensada para figurar como espaço estático, a enfatizar a hegemonia do saber, gradativamente ela vem tomando consciência da necessidade de dinamização do seu espaço, de modo a contemplar todas as possibilidades mediacionais, abrir o diálogo e interagir com a sua comunidade, convidando-os a se sentirem parte deste processo de mudança. 
Por fim, este estudo propôs uma interlocução entre a mediação da informação, as narrativas orais e histórias de vida, no intuito de identificar e posteriormente compreender o processo de mediação utilizando o prisma da oralidade. Ponderamos dessa forma que o objetivo de apresentar a tipologia da mediação informacional dialogada com a técnica da narrativa oral sob a perspectiva das histórias de vida foi alcançado.

Como conclusão, constatamos que as narrativas orais e histórias de vida apresentam grandes potencialidades como fenômeno mediacional para a apropriação de informações e construção de conhecimento.

\section{REFERÊNCIAS}

ALBERTI, Verena. Narrativas na história oral. In: SIMPÓSIO NACIONAL DE HISTÓRIA, 22., 2003, João Pessoa. Anais eletrônicos... João Pessoa: ANPUH-PB, 2003. Disponível em: $<$ http://bibliotecadigital.fgv.br/dspace/bitstream/handle/10438/6705/1346.pdf? sequence=1\&is Allowed=y>. Acesso em: 6 dez. 2017.

ALBERTI, Verena. História Oral: a experiência do CPDOC. Rio de Janeiro: Centro de Pesquisa e Documentação de História Contemporânea do Brasil, 1989.

ALMEIDA, Marco Antônio de. Mediação cultural e da informação. In: ENCONTRO NACIONAL DE PESQUISA EM CIÊNCIA DA INFORMAÇÂO, 8. 2007, Salvador. Anais... Salvador: UFBA, 2007. p. 1-16.

ALMEIDA JÚNIOR, Oswaldo Francisco de. Mediação da informação e múltiplas linguagens. Pesq. bras. Ci. Inf., Brasília, v.2, n.1, p.89-103, jan./dez. 2009. Disponível em: $<$ https://www.researchgate.net/publication/277162051_MEDIACAO_DA_INFORMACAO_ E_MULTIPLAS_LINGUAGENS >. Acesso em: 4 dez. 2017.

ALMEIDA JÚNIOR, Oswaldo Francisco de. Mediação da informação: discutindo a atuação do bibliotecário. In: FADEL, Bárbara. A Informação nas organizações sociais: desafios em face de multiplicidade de enfoques. Marília: FUNDEPE, 2004. p. 209-217, p. 214.

BAJARD, Elie. Ler e dizer. 3. ed. São Paulo: Cortez, 2001.

BATTISTELLA, Laoderene; SOUZA, Andréia Cristina de. A oralidade no processo de construção do conhecimento no CEEBJA. Cadernos PDE, Paraná, v. 1, p. 1-15, 2013.

BORTOLIN, Sueli. Mediação oral da literatura: a voz dos bibliotecários lendo ou narrando. 2010. 234 f. Tese (Doutorado em Ciência da Informação)-Faculdade de Filosofia e Ciências, Universidade Estadual Paulista Júlio de Mesquita Filho, Marília, 2010.

BOSI, Ecléa. O tempo vivo da memória: ensaios de psicologia social. São Paulo: Ateliê Editorial, 2003.

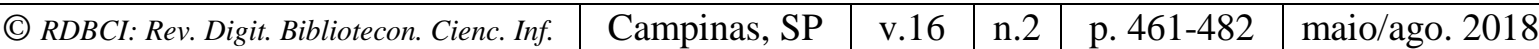


CARVALHO, Luciana Moreira. Atuação de bibliotecários em bibliotecas universitárias brasileiras e portuguesas: espaço de mediação custodial ou pós-custodial. In: ENCONTRO NACIONAL DE PESQUISA EM CIÊNCIA DA INFORMAÇÃO, 16., 2015, João Pessoa. Anais... João Pessoa: UFPB, 2015. p. 1-18.

CAVALCANTE, Lidia Eugênia. Diálogos entre informação social, mediação cultural e comunidade. In: BELLUZZO, Regina Célia Baptista; FERES, Glória Georges; VALENTIM, Marta Lígia Pomim (Orgs.). Redes de conhecimento e competência em informação: interfaces da gestão, mediação e uso da informação. Rio de Janeiro: Interciência, 2015. p. $399-414$.

CAVALCANTE, Marianne C. B.; MELO Cristina T. V. Gêneros orais na escola. In: SANTOS Carmi. F.; MENDONÇA, Márcia; CAVALCANTE, Marianne C. B. (Orgs.) Diversidade textual: os gêneros na sala de aula. Belo Horizonte: Autêntica: 2007. p. 89-102. Disponível em:

$<$ http://www.nigufpe.com.br/wpcontent/uploads/2012/09/Diversidade_Livro.pdf > . Acesso em: 9 dez. 2017.

CHARTIER, Roger. Formas e sentido: cultura escrita: entre distinção e apropriação. Campinas: Mercado das Letras; Associação de Leitura do Brasil, 2003.

FARIAS, Maria Giovanna Guedes. Mediação e competência em informação: proposições para a construção de um perfil de bibliotecário protagonista. InCID: Revista de Ciência da Informação e Documentação, Ribeirão Preto, v. 6, n. 2, p. 106-125, set. 2016.

FERNANDES, Maria das Graças Melo; LOUREIRO, Lara de Sá Neves. Memória e história oral: a arte de recriar o passado de idosos. A Terceira Idade: estudos sobre envelhecimento, São Paulo, v. 20, n. 45, p. 53-66, jun. 2009.

FONSECA, Edson Nery da. Introdução à biblioteconomia. 2. ed. Brasília: Briquet de Lemos Livros, 2007.

HAVELOCK, Eric. A revolução da escrita na Grécia e suas consequências naturais. Tradução Ordep José Serra. São Paulo: Ed. UNESP; Paz e Terra, 1996.

MARTINS, Ana Amélia Lage. Mediação e bibliotecas públicas: uma perspectiva dialética. Perspectivas em Ciência da Informação, Belo Horizonte, v. 19, p. 164-185, dez. 2014.

MEDEIROS, Vera Lucia Cardoso. Quando a voz ressoa na letra: conceitos de oralidade e formação do professor de literatura. Manda El-rei que eu conte outro: literaturas da voz da modernidade, Porto Alegre, v. 21, n. 42, p.69-84, jan. 2007.

ONG, Walter. Oralidade e cultura escrita: a tecnologização da palavra. Campinas: Papirus, 1998. 
PERAZZO, Priscila F. Narrativas orais de histórias de vida. Comunicação e inovação, São Caetano do Sul, v. 16, n. 30, p. 121-131, jan./abr. 2015.

QUEIROZ, Maria Isaura Pereira de. Relatos orais: do indizível ao dizível. In: VON SIMSON, Olga Morais (org.). Experimentos com história de vida: Itália-Brasil. São Paulo: Vértice, 1988.

RODRIGUES, Maria Fernanda. A biblioteca do futuro não terá o livro como centro de gravidade, diz Mélanie Archambaud. O Estado de São Paulo, São Paulo, 20 nov. 2017. Disponível em: <http://cultura.estadao.com.br/noticias/literatura,a-biblioteca-do-futuro-naotera-o-livro-como-centro-de-gravidade-diz-melanie-archambaud,70002090284 >. Acesso em: 11 dez. 2017.

SÁ, José Marcílio de. José Marcílio de Sá: depoimento oral [dez. 2017]. Entrevistadora: Ana Cristina Guimarães Carvalho. Teresina, 2017.

SANCHES, Gisele. A. Ribeiro; RIO, Sinomar. Ferreira. Mediação da informação no fazer bibliotecário no âmbito das ações culturais. InCID: Revista de Ciência da Informação e Documentação, Ribeirão Preto, v. 1, n. 2, p. 103-121, jul./dez., 2010.

SANTOS NETO, João Arlindo dos. Mediação implícita da informação no discurso dos bibliotecários da biblioteca central da Universidade Estadual de Londrina (UEL). 2014.

193 f. Dissertação (Mestrado em Ciência da Informação)-Universidade Estadual Paulista, Marília, 2014. Disponível em: <https://repositorio.unesp.br/handle/11449/110288>. Acesso em: 4 dez. 2017.

SANTOS NETO, João Arlindo dos; ALMEIDA JÚNIOR, Oswaldo Francisco de. A competência em Informação e o bibliotecário mediador da informação na biblioteca universitária. In: BELLUZZO, Regina Célia Baptista; FERES, Glória Georges; VALENTIM, Marta Lígia Pomim (Org.). Redes de conhecimento e competência em informação: interfaces da gestão, mediação e uso da informação. Rio de Janeiro: Interciência, 2015. p. 359-376.

SILVA, Jonathas Luiz Carvalho. Como atuar com dinamização de acervos em ambientes de informação? Infohome, São Paulo, Abr. 2017. Disponível em:

<http://www.ofaj.com.br/colunas_conteudo.php?cod=1046>. Acesso em: 29 dez. 2017.

SILVA, Jonathas Luiz Carvalho. Percepções conceituais sobre mediação da informação. InCID: Revista de Ciência da Informação e Documentação, Ribeirão Preto, v. 6, n. 1, p. 93108, mar./ago. 2015. Disponível em: <http://dx.doi.org/10.11606/issn.2178-2075.v6i1p93108>. Acesso em: 4 dez. 2017.

SOUSA, Laiana Ferreira de; LIMA, Izabel França de. Encontro com as memórias leitoras do bibliotecário contador de histórias. In: ENCONTRO NACIONAL DE PESQUISA EM CIÊNCIA DA INFORMAÇÃO, 17., 2016, Salvador. Anais... Salvador: UFBA, 2016. p. 120.

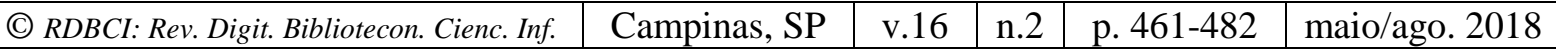



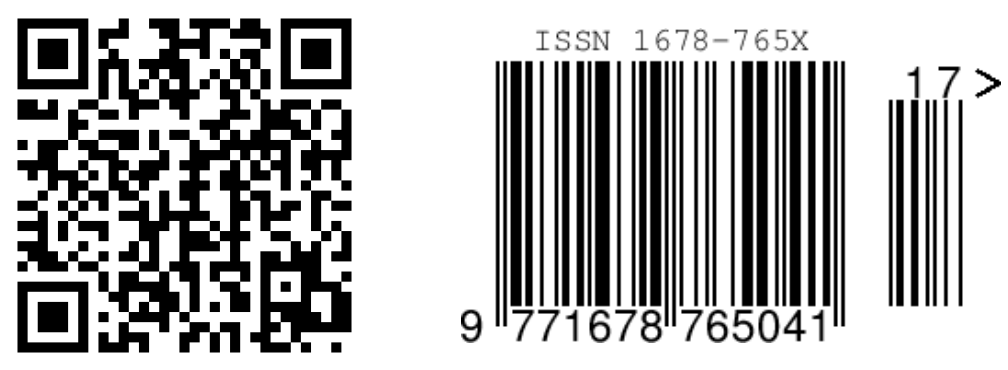